Autor invitado

Jorge AlBISTUR*

Universidad de la República (Uruguay)

jaurenio@gmail.com

\title{
Persiles: desde un lugar de la Mancha a los confines del mundo
}

\author{
Persiles: from a village of la Mancha to the \\ confines of the world
}

\begin{abstract}
Resumen: Obra póstuma, Los trabajos de Persiles y Sigismunda ha sido tenida, ateniéndose a la posible fecha de composición y casi inexplicablemente, como la primera y la última obra de Cervantes. Una buena lectura exige despejar el asunto de su ubicación cronológica, pues hacerlo ayuda a situar correctamente al Persiles en el conjunto de la producción cervantina. Los siglos han interpretado la novela de modos bien distintos, como igualmente la Ilustración, el romanticismo y el 98 leyeron un Quijote diferente. En la conmemoración del cuarto centenario de la muerte de Cervantes, es bueno revisar las lecturas del pasado. Es tarea necesaria, asimismo, explorar en las etimologías, los símbolos y los episodios alegóricos que pueden iluminar un mensaje de la novela. En nuestra opinión, ese mensaje es confirmatorio del Cervantes librepensador y erasmista, adelantado a su tiempo, que se ha visto a partir del Quijote. Unas páginas del Persiles asoman a otra cuestión, singularmente importante cuando se lee en estos litorales: la presencia de América en la obra de Cervantes. De tal modo pasea su mirada curiosa por todas las fronteras del universo conocido.
\end{abstract}

Palabras clave: Persiles - peregrinación atlántica - símbolos - Tule - erasmismo

\begin{abstract}
The Wanderings of Persiles and Sigismunda is a posthumous novel that, due to its date of writing and yet almost inexplicably, has been conceived as the first and last work of Cervantes. For its accurate reading, it is vital to clarify its chronological location, since this is what allows to correctly place the Persiles in the whole of the Cervantine production. Throughout the centuries, the novel has been interpreted very differently, just in the same way that the Enlightenment, the Romanticism and the Generation of '98 read a different Quixote. In the 4th Centenary of the death of Cervantes, it is pertinent to review past readings. Additionally, it is necessary to explore the etymologies, the symbols and the allegorical passages that can shed light on a possible new message of the novel. To our mind, this message confirms the existence of Cervantes as a freethinker and an Erasmist writer, and as the man ahead of his times that has been studied ever since the publication of Don Quixote. Some of the pages of Persiles introduce another matter, which is of singular importance when the novel is read in this side of the world: the presence of America in the work of Cervantes. In this way, Persiles casts a curious look on all the borders of the known universe.
\end{abstract}

Keywords: Persiles - Atlantic Pilgrimage - symbols - Tule - Erasmism

Profesor de Literatura, egresado del Instituto de Profesores «Artigas» (IPA). Docente en Educación Secundaria y de Literatura Española en el IPA y -grado 5- en la Facultad de Humanidades y Ciencias de la Educación de la Universidad de la República. Ha publicado trabajos relacionados con Cervantes, entre ellos, Leyendo elQuijote, cuya primera edición es de 1968. 


\section{El primero o el último; el mejor o el peor}

Es difícil escribir sobre el Persiles sin recordar unos versos que Cervantes cita, pues los recoge de la tradición anónima, y que parecen concebidos como advertencia a críticos indiscretos y empeñados en racionalizarlo todo. Se lee, en el Libro Tercero, capítulo XIII: ${ }^{1}$ «Las cosas de admiración / no las digas ni las cuentes / que no saben todas gentes / cómo son». La maravilla se muestra, no se explica. El albaceazgo en torno a «las cosas de admiración», por lo tanto y en todo caso, solo cobra algún sentido si se lo concibe como ayuda a la epifanía. Nuestro homenaje al Persiles es pues, antes que nada, una preparación para el reencuentro con la novela en la conmemoración del cuarto centenario de la muerte de Cervantes.

Esta módica tarea alcanza su verdadera dimensión si se tiene en cuenta que, de todas las obras de Cervantes y si se exceptúa a la Galatea, el Persiles es la menos leída en estos últimos años. Las Ejemplares le llevan ventaja por la brevedad, pero también por ofrecer los vivos cuadros de la realidad europea -no ya española- en los tiempos augurales de la modernidad. La novela bizantina -los lobos que hablan, las alfombras que vuelan, los corceles que caen por interminables precipicios y galopan otra vez apenas tocan el suelo, las doncellas cuya virtud se mantiene invicta aun prisioneras de canallas rijosos-toda esta profusión fantástica nos es hoy singularmente ajena, ya que en todo caso imaginamos hacia muy otros delirios. Pero todo esto, además, nos resulta extraño al espíritu de Cervantes, a la sorna del Quijote, a ese aire irónico y al mismo tiempo tierno en el cual reconocemos una sensibilidad y una filosofía de vida. El Persiles no parece de Cervantes y sobre todo no parece una obra del escritor maduro, un libro posterior al Quijote.

El desconcierto que su lectura provoca explica una rara controversia. Ella discute cómo ubicar al Persiles en el conjunto de la obra cervantina: una polémica que se proyecta al juicio que merezca la novela, como si ella no valiese por sí misma sino representando un punto cardinal en el universo del autor. Vale la pena detenerse un momento en esta problemática, pues la discusión oscila entre considerar al Persiles como la primera o la última obra de Cervantes, y no es la menor «cosa de admiración» que así, como extremos tan distantes, pueda verse un mismo texto.

1 El Persiles se divide en cuatro libros, todos ellos subdivididos a la vez en varios capítulos. En adelante, toda referencia al texto será en números romanos: el primero corresponde al libro; el segundo, al capítulo. Aquí, por ejemplo, sería: III, XIII. 
El Persiles es, como bien se sabe, una obra póstuma, que apareció por primera vez en 1617. La objetividad de esta circunstancia no impidió, sin embargo, la duda acerca de la fecha o fechas de su composición, pues no es imposible que se publique, mucho tiempo más tarde y muerto ya el escritor, una obra escrita años y aun décadas atrás. El principal defensor de esta posibilidad fue el crítico estadounidense Max Singleton, cuyo trabajo no ha sido reeditado -que se sepa- pero pudo leerse en español en la revista Realidad. ${ }^{2}$

Considerada la endeble condición de las argumentaciones de Max Singleton, casi podría decirse que él partió de sus íntimas convicciones luego de leer el Persiles, y buscó luego las pruebas de que ella es una obra juvenil, en lugar de recorrer el camino opuesto y mejor legitimado como fundamento de una tesis. Max Singleton no tiene, efectivamente, nada, salvo una imperativa negación cuando imagina un Cervantes dispuesto a vivir horas de niño a las puertas de la muerte: alguien que, después de combatir a las novelas de caballerías volviera nuevamente a ellas -el Persiles es, «psicológicamente», una novela de caballerías, dice Ángel Valbuena Prat ${ }^{3}$ - y se reconciliase con la fantasía. Max Singleton debió sentir que, si el Persiles es la última obra de Cervantes, él pudo entonces escribirlo arrepentido de su Quijote. El crítico debió también pensar que el escritor se convertía en alguien inconsciente de su propio mensaje: algo así como ese Cervantes que creyó ver Unamuno, poseído y superado por don Quijote e incapaz de comprender su propia creación. Que Max Singleton cree en dos Cervantes irreconciliables está fuera de discusión: para él el Persiles está del lado de la Galatea, de la cual es, a su juicio, contemporáneo, y del otro lado está el Cervantes «realista»-cabe simplificar y aceptar al menos por ahora este término- que escribe el Quijote, lo mejor de las Ejemplares y buena parte del teatro. De este último lado está, en fin, Cervantes, tal como lo concibe y admira el crítico.

La fuerza de Max Singleton deviene, probablemente, de cómo él coincide, en lo esencial, con innumerables lectores de Cervantes. Hoy ya casi nadie lo cita, y pocos lo toman demasiado en serio, pero él es el abanderado de esa lectura desconfiada del Persiles - por así llamarla- que es todavía frecuente. El Persiles-se piensa- no es obra «madura». Equivale a una especie de retroceso: como asustado por la densidad de su Quijote, Cervantes vuelve a jugar y en una triunfal fiesta lúdica abre de par en par las puertas a la imaginación sin

2 Cfr. Max Singleton: El misterio del Persiles. En: Realidad, n 5, Homenaje a Cervantes, Buenos Aires, setiembre-octubre de 1947, pp. 237-53.

La llama «poemática novela de caballerías que rectifica el fracaso del héroe en don Quijote». Ángel ValBuena PRAT: Historia de la literatura española. Tomo II. Gustavo Gili, Barcelona, 1953. 
barreras. Tal vez todo sea bien distinto, y el Persiles contenga una síntesis de las preocupaciones centrales de Cervantes y, aunque sea difícil de hallar, contenga también el corazón de sus respuestas a las grandes interrogantes del Quijote y el resto de su obra.

Pero antes de abordar la empresa de insinuar que así es, en efecto, es bueno volver por un instante al crítico más severo del Persiles, tan intolerante con ese otro Cervantes que le hurtaba su Cervantes admirado y querido. Max Singleton entusiasmó a Luis Rosales: ${ }^{4}$ lo entusiasmó sobre la base de un singular equívoco, pues Rosales estimaba al Persiles como una verdadera maravilla y no pareció darse cuenta de hasta dónde Max Singleton desaprobaba la novela. La consideró, en efecto, un libro fracasado, y hasta confesó que veía más «pulimento»y «coherencia» en la Galatea que en el Persiles. Consideraba a este último como el ensayo infeliz de un principiante. Su tesis se completa con estas suposiciones: Cervantes habría consentido en publicar aquel esbozo juvenil cuando se sintió morir, pues entonces -ya que las cuestiones económicas no andaban nada bien- prometió a la familia, y se prometió a sí mismo, dar a las prensas todo lo que pudiera significar algún dinero. El crítico, convertido en un biógrafo muy imaginativo, supone también que Cervantes pudo confiar en que sus íntimos, sabedores de que el Persiles era obra juvenil, lo aclararían para la posteridad. Todo lo cual significa pensar a Cervantes como alguien atento y preocupado por lo inmediato -no tenía ni leña en el último invierno que pasó en Valladolid-y también por el porvenir de su memoria, inquietud que tan presente parece estar en el final del Quijote, por ejemplo.

No sería sensato ir adelante sin recoger las objeciones precisas que mereció en su momento la tesis de Max Singleton. ${ }^{5}$ Una tiene que ver con la alusión al caso Ezpeleta, aquel hombre que apareció muerto a las puertas de la casa de Cervantes en Valladolid. ${ }^{6}$ El suceso ocurrió en 1605, de modo que el correspondiente pasaje del Persiles no puede ser anterior a esa fecha. Estaríamos hablando, en consecuencia, de una redacción en fecha no más temprana que el primer Quijote, por lo menos. Un razonamiento parecido resulta de aceptar la influencia de un pasaje de los Comentarios reales del Inca Garcilaso sobre el Persiles. ${ }^{7}$ La obra se publicó en 1609, de modo que mal

\footnotetext{
Cfr. Luis Rosales: Cervantes y la libertad. Editorial Trotta, Madrid, 1996

El tema fue abordado por Vicente GAos en Cervantes novelista, dramaturgo y poeta. Planeta, Barcelona, 1979; y Juan Bautista Avalle Arce: Introducción. En: Miguel de Cervantes: Los trabajos de Persiles y Sigismunda. Castalia, Madrid, 1969.

6 Miguel de Cervantes: Los trabajos de Persiles y Sigismunda. Juan Bautista Avalle Arce (ed.). Castalia, Madrid, 1969, III, IX.

Miguel de Cervantes: Los trabajos de Persiles y Sigismunda. I, V y VI.
} 
pudo Cervantes conocerla e inspirarse en ella con anterioridad a esa fecha. El estudiante que aparece en el Prólogo del Persiles, por otra parte, es el mismo que festeja a Cervantes en Viaje del Parnaso, libro de 1614, aunque una refutación fundada en esto sería poco firme, pues Cervantes pudo escribir el Prólogo -como efectivamente lo hizo, y también la Dedicatoria- recién cuando decidió publicar el libro aun cuando fuese obra juvenil. Pero la perla de todo este asunto es la mención de Felipe Tercero, ${ }^{8}$ palabra esta última que Max Singleton -resuelto a defender hasta el final su peregrina teoríaconsidera agregada por el editor para «remozar» y poner al día, por así decir, una obra que también él sospechaba vieja y pasada de moda en los tiempos de su tardía aparición.

El buen Max Singleton pasa como sobre ascuas por las abundantes menciones al Persiles en el resto de la obra cervantina: comentarios siempre sobre una obra en proceso de redacción y bastante antes del momento final en la vida del autor. Así, hay referencias en el Prólogo a las Ejemplares, en la Dedicatoria a la Segunda Parte del Quijote y en Viaje del Parnaso. Podría ir en ayuda de Max Singleton la sobriedad de Cervantes en este último caso, tanto más notable si se la contrasta con los consabidos auto-elogios de Cervantes. Dice, parcamente, aquí: «Yo estoy, cual decir suelen, puesto a pique / para dar a la estampa al gran Persiles, / con que mi nombre y obras multiplique». ${ }^{9}$ Aun considerado aquello del «gran Persiles», mucho más entusiasmado se muestra en la Dedicatoria a la Segunda Parte del Quijote, pues allí se refiere a:

Los trabajos de Persiles y Sigismunda, libro a quien daré fin dentro de cuatro meses, Deo volente; el cual habrá de ser o el más malo o el mejor que en nuestra lengua se haya compuesto, quiero decir de los de entretenimiento; y digo que me arrepiento de haber dicho el más malo, porque según la opinión de mis amigos ha de llegar al extremo de la bondad posible. ${ }^{10}$

Todas estas menciones descalifican, o casi, la opinión de Max Singleton y sugieren que, si fue obra juvenil en sus orígenes, el Persiles ocupó a Cervantes, en su corrección o continuación, muchos años centrales en su madurez creadora.

Miguel de Cervantes: Los trabajos de Persiles y Sigismunda. III, VII.

Miguel de Cervantes: Viaje del Parnaso. Capítulo IV.

${ }^{10}$ Miguel de Cervantes. El ingenioso hidalgo Don Quijote de la Mancha. Edición de la Asociación de Academias de la Lengua Española, Madrid, 2005. 


\section{A través de los siglos}

Sea como fuere, si no se acepta la tesis de Max Singleton y si se considera al Persiles como la última obra de Cervantes, el Quijote ocupa un lugar bien singular en el conjunto. Equivale a un fuerte reclamo de la «realidad» entre dos mundos de sueño. La Galatea en la juventud y el Persiles en la vejez son el triunfo de la fantasía. El Quijote, la imposibilidad de la aventura, tenazmente negada por un mundo gris y prosaico. Cuando, derrotado ya el caballero andante, don Quijote proyecta hacerse pastor, Cervantes parece arremeter contra el otro espejismo de los Siglos de Oro. La caballería en la guerra y el ocio pastoril en la paz tenían en común una misma ebriedad evasiva, y contra ella va la lucidez ubicua de Cervantes en el Quijote. Esta novela trata verdades, y son «verdades tan lindas y tan donosas que no puede haber mentiras que se le igualen»: la frase aparece en el capítulo xxi de la Primera Parte y es un elogio de la novela picaresca, si el pícaro contara alguna vez él mismo sus andanzas.

Ahora bien: esta visión del Quijote como alternativa realista a los mundos fantásticos no deja de ser una simplificación peligrosa. El «realismo» del Quijote, en efecto, puede ser cuestionado de mil modos, y hasta podría decirse que nada hay menos creíble que el personaje principal: ese cincuentón tímido y dueño de muchos libros que de pronto soportará, sin doblegarse jamás, las noches al sereno, la comida mala y escasa y el asedio moral de esa risa de los otros que responde a menudo a sus más generosas acciones. La fuerza interior, y aun física, de este hombre, no es verosímil, y desde tal protagonista la inverosimilitud se proyecta hacia todos los rincones de la novela.

Antes que cartografiar polos en el universo cervantino -tentación a la que sucumbió al fin Max Singleton- y hablar de los extremos de realismo y fantasía, sería mejor reconocer, con Riley, ${ }^{11}$ que Cervantes nunca se decidió del todo en esta encrucijada y dejó por todas partes el testimonio de su indefinición tan claramente como si deseara subrayar, además, el carácter deliberado de su doble opción. En el Quijote, la novela «realista» que ha impulsado cierta crítica española, aparecen la pastora Marcela y el cautivo. En las Ejemplares, junto a Rinconete y Cortadillo, están La española inglesa y La fuerza de la sangre. La diversidad es allí tan notoria, que hasta se propone frecuentemente dividir las Ejemplares en dos grupos, y estudiar por un lado las costumbristas, por así decir, y por otro las inspiradas en la narración corta italiana. ¿Qué hacer,

${ }^{11}$ Cfr. Edward C. Riley: Teoría de la novela en Cervantes. Taurus, Madrid, 1971. 
dicho sea de paso, con La gitanilla, que parece concebida como una síntesis de ambas direcciones? A la gitana -en la cual, por otra parte, nadie reconocería sin más al «tipo» que ofrecía por entonces la realidad española- le ocurren las cosas milagrosas de los relatos a la italiana. En el Quijote, en las Ejemplares, en el Persiles o donde sea, Cervantes concilia siempre los opuestos aparentes y esta combinatoria no puede sorprender en aquel siglo XVII empeñado siempre en recorrer las áreas linderas de dos territorios igualmente atractivos. Al fin y al cabo Shakespeare, ilustre contemporáneo de Cervantes, pintaba como nadie la verdad de las pasiones pero se distraía, de pronto, con Sueño de una noche de verano, o poblaba el escenario de hadas y de espectros.

Aunque también ubicado en este punto de cruce entre el testimonio y la ficción -como se verá en adelante- el Persiles es visto pues, en la posteridad, como novela de la fantasía. Es visto también, y pese a los esfuerzos de Max Singleton, como la última obra de Cervantes. La valoración que los lectores hicieron de la novela, por otra parte, es tan variada, que hasta podría escribirse una historia de las lecturas del Persiles, como efectivamente se ha hecho con respecto al Quijote, para recoger la diferente sensibilidad con que lo han recibido épocas y hombres distintos. Llamaría la atención, entonces, comprobar que el siglo XVIII lo tuvo, en general, como un libro tan excelente como el propio Quijote, si no mejor todavía que la famosa novela. Joaquín de Casalduero, por ejemplo, transcribe dos juicios reveladores en este sentido. ${ }^{12}$ Uno, el de Valdivielso, que vale la pena copiar aquí aunque refleje una opinión del siglo XVII: «De cuantos libros nos dejó escritos ninguno es más ingenioso, más culto ni más entretenido; en fin, cisne de su buena vejez». ${ }^{13}$ Otro, de Federico von Schlegel, quien escribió: «Es el más tardío, casi demasiado maduro, pero, no obstante, fresco y aromático fruto de este amable ingenio, quien aún en su último aliento respiraba poesía y eterna juventud». ${ }^{14} \mathrm{En}$ estos juicios, como se ve, el Persiles es tenido por obra de la vejez: impresión que el libro causa por sí mismo y se imponía naturalmente en aquellos años, cuando todavía no había Max Singleton alguno que sostuviese lo contrario.

También así lo leyó Menéndez Pelayo, cuya opinión, favorable pero solo relativamente entusiasta, refleja una manera nerviosa y lacónica de juzgar lo que estudiaba largamente, pues encerró sus impresiones en casi esta sola

12 Cfr. Joaquín Casalduero: Sentido y forma de Los trabajos de Persiles y Sigismunda. Gredos, Madrid, 1975.

13 José de Valdivielso (1565-1638), poeta y autor dramático contemporáneo de Cervantes, que logró el pequeño milagro de ser su amigo y, al mismo tiempo, llevarse bien con Lope de Vega.

${ }^{14}$ Hispanista alemán (1772-1829), hermano del también filólogo August Wilhelm von Schlegel. Ambos ocuparon un importante lugar entre los fundadores del romanticismo. 
frase: «Puesta de sol es el Persiles, pero todavía tiene resplandores de aurora». ${ }^{15}$ Esta economía dejaba ver, de todos modos, que el crítico es una excepción, y no la única, en un panorama bien adverso al Persiles en los siglos XIx y Xx. Tal vez porque el romanticismo y el 98 enaltecieron al Quijote -haciéndole decir lo que ellos deseaban hallar en las obras maestras- y relegaron al Persiles, tal vez por estas razones cree Casalduero que a las dos últimas centurias les cupo la triste tarea de hacer que la última obra de Cervantes no se leyera. El silencio, en el siglo XIX, es un poco ensordecedor, pero cabe reconocer que, entonces, el Quijote le robó a Cervantes casi todo el resto de su producción, así que el olvido del Persiles es tan solo un capítulo en un proceso complejo.

En el siglo xx, los tópicos críticos a propósito del Persiles han sido los siguientes: recoger y comentar la frase «todos mis bienes son soñados», ${ }^{16}$ tomada como clave de la novela; repetir, sin más, la inexacta afirmación según la cual hay dos libros vivaces, los dos últimos, y dos monótonos; afirmar-cosa que hace el propio Cervantes- que la novela se inspira en Teágenes y Cariclea del bizantino Heliodoro; sostener que el Persiles supera al Quijote en materia de estilo, valoración insostenible, como habrá de verse, salvo si se considera que el mejor estilo es el pulcro y académico, aquel que no consiente giros populares ni siquiera cuando hablan personajes que no pertenecen a la nobleza.

Claro es que hay excepciones, en los siglos XIX y Xx, a la tendencia que convirtió al Persiles en «la cenicienta de las obras de Cervantes», como la llamaba Américo Castro. El surrealismo trajo cierto viento a favor, pues ya se sabe que, en español, debería hablarse de «sobrerrealismo»: vale decir, de algo que está por encima y más allá del realismo, así que el eje de esta corriente venía a coincidir con lo central del último Cervantes. El éxito del llamado «boom» latinoamericano, allá por los 70, fue también un momento de importantes revisiones. Carpentier y Vargas Llosa relacionaron a la novela americana, y su realismo mágico, con los libros de caballerías y formas afines de la imaginación en los Siglos de Oro, de modo que el Persiles recuperó, aunque sin ser leído, cierta actualidad.

En España, un esfuerzo decisivo en la reestimación corrió a cargo de Azorín, cuyos estudios, como siempre, no pretenden alcanzar una interpretación coherente y completa sino anotar meditaciones sobre un fragmento, o un

\footnotetext{
15 Menéndez Pelayo se refirió al Persiles en numerosas oportunidades, entre otras en el estudio Cultura literaria de Cervantes y elaboración del Quijote, que aparece en las Obras completas publicadas por Espasa Calpe a lo largo de varios años.

16 Miguel de Cervantes: Los trabajos de Persiles y Sigismunda, II, XVI.
} 
detalle de estilo, o bien prolongar las sugerencias del texto cervantino. Esta crítica es «impresionista»: así la califica, o descalifica, Casalduero, y pone en guardia contra lo que ve como una especie de vicio. Azorín lo sintetiza todo, de pronto, en un solo adjetivo, que el lector habrá de entender, además, según su propia experiencia de la vida y la cultura. Se pregunta, por ejemplo, a propósito de un monarca que pierde su corona por ceder a la lujuria: «ن $Y$ este rey Policarpo, rey shakespeariano?». Con referencia a toda la novela, y su mensaje, dice Azorín: «Todos deseaban, pero a ninguno se le cumplían sus deseos, escribe el poeta. Un deseo siempre anheloso, un deseo errante por el mundo, un deseo insatisfecho, un deseo que siempre ha de ser deseo: eso es el libro de Cervantes». ${ }^{17}$

No estará de más recordar este sencillo juicio a la hora de acercarnos por fin a las lecciones y moralejas encubiertas, a los acertijos y simbolismos de una obra difícil. Ella enseña antes que nada esta vieja verdad: vivir es desear. $Y$ tal vez pensando en la fáustica insatisfacción del hombre agregaba Azorín que el Persiles es un libro «trágico». El deseo sustituye siempre una cosa por otra, y por eso todos los bienes son soñados: apenas alcanzados, nuevos espejismos dejan entrever también nuevos oasis. Quizá por esta eternidad del deseo veía Azorín, en el Persiles, «el libro admirable de un gran poeta». ${ }^{18}$ 
llega a Roma persiguiendo a esta mujer maravillosa. Este otro pretendiente muere en Roma, pero no sin antes consentir el matrimonio de Persiles y Sigismunda. Los protagonistas vuelven desde allí a Tule, en retorno que ya no se cuenta, para gozar de la felicidad que tan trabajosamente han conquistado.

En torno a este asunto central, se desenvuelven las mil peripecias de un viaje azaroso, aunque con destino perfectamente fijo. La novela comienza cuando la pareja está cautiva en una isla bárbara, poblada por gente hostil y que amenaza la vida de Persiles y la castidad de Sigismunda. Desde allí se suceden los incidentes, narrados en cuatro libros. Los dos primeros transcurren en el océano, donde aparecen monstruos y piratas y no faltan los naufragios. La nave de los enamorados toca al fin Lisboa, y el viaje se extiende desde allí a tierras de Portugal, España, Francia e Italia. Suele decirse que Cervantes se mueve más cómodo en los últimos dos libros, cuando los personajes están en territorio europeo, aunque más de un lector ha preferido la primera mitad -los dos libros iniciales- que nos enfrenta a un Cervantes capaz de inventar un mundo por entonces remoto e ignorado. El destino final no es Roma sino Tule, tierra retirada y último confín conocido: asunto principalísimo al reflexionar sobre el posible mensaje de la novela.

Algo, sin duda, llama la atención en todo esto, antes que cualquier otra consideración, y es la elección de los nombres de los personajes. Los fingidos y los verdaderos apuntan a significaciones transparentes. «Periandro» es «lo que rodea al hombre», y «Auristela» encubre apenas a la «estrella de oro». «Persiles» es «Per silens», el silencioso, el más callado, en tanto «Sigismunda» es aquella que lleva «el sello de lo puro». Estos nombres designan probablemente a Cristo -el callado, hombre entre los hombres pero hijo de Dios- y a su Iglesia, distinguida entre todas las comunidades por el signo de la autenticidad, pues es la casa del dios verdadero. «Munda» es para Cervantes igual a «pura», porque en su sentido etimológico lo mundo es lo puro, como lo inmundo es lo impuro. No importa aquí que en toda su obra se muestre Cervantes consciente de que nada es más inmundo que el mundo: se mantuvo de todos modos fiel a la etimología, pues Rosamunda, la prostituta del Persiles, es la rosa inmunda, la que ha asumido totalmente la lujuria simbolizada por la reina entre las flores. ${ }^{19}$ Un ejercicio parecido podría practicarse a propósito de otros nombres de personajes en la novela. Se volverá a este aspecto cuando resulte

19 «Oh Rosamunda, o por mejor decir, Rosa inmunda!, porque munda, ni lo fuiste, ni lo eres, ni lo serás en tu vida!» En: Miguel de Cervantes: Los trabajos de Persiles y Sigismunda, I, XIV. 
conveniente, pero es bueno advertir que este tipo de análisis se ha planteado con frecuencia al estudiar el Persiles.

Preferible será recorrer ahora las grandes avenidas para el buen acceso a la novela. Ella es, en primer lugar, la novela universal de Cervantes. Geográficamente, aunque hablando ya no de geografía física sino antes humana, cabe aceptar esta síntesis: el Quijote es España; las Ejemplares, Europa; el Persiles, el mundo occidental hasta entonces conocido, sin excluir América, continente del cual tenía Cervantes buena información, puesto que proyectó en algún momento venir a estas tierras para tentar fortuna. El fue uno más en el sueño de «hacerse la América». La curiosidad por las Indias - pues la palabra «América» aparece poco en Cervantes- se refleja en algún pasaje famoso del Persiles, como habrá de verse. Entretanto, y cediendo a la pésima costumbre de citarse a sí mismo, el autor de estas líneas recuerda que ha escrito un estudio sobre Cervantes y América ${ }^{20}$ y remite además, en cuanto a las Ejemplares se refiere, a la versión escrita de su conferencia sobre estas novelas, dictada en la Universidad de la República (Uruguay) en 2013. ${ }^{21}$ Allí se verá cómo los doce relatos se pasean desde Milán a Londres, por ejemplo, ofreciendo escenarios bien distintos a los del Quijote, reducido a un bien cartografiado recorrido por tierras estrictamente españolas.

El Quijote es, además, la novela rural de Cervantes, y esto porque España misma fue un país predominantemente rural cuando Europa en general había entrado ya en la cultura de las ciudades. Al caballero andante, si bien se lee, lo derrota la ciudad: su vencimiento ocurre en Barcelona y esta circunstancia está llena de sentido. La conferencia mencionada desarrolla también este aspecto, y llama la atención sobre el mejor trabajo escrito en el Uruguay sobre el tema de Cervantes y las ciudades: el de Álvaro Figueredo, poeta azuqueño -de Pan de Azúcar- que volcó allí, tal vez, su propia reserva sobre las excelencias de la vida urbana. ${ }^{22}$

Vale la pena asomar todavía a otra avenida hacia una buena lectura del Persiles. Es la obra en la que Cervantes deja atrás, por fin, la gran miopía que cegó casi su visión de muchos años sobre la historia y el destino de Europa.

20 Jorge Albistur: Cervantes y América. En: Cuadernos hispanoamericanos, n 463, Madrid, 1989, pp. 65-72.

${ }^{21}$ Jorge Albistur: Las Ejemplares: «mostrar con propiedad un desatino». En: María de los Ángeles GonzÁLEZ BrIZ (ed.): Barroco, sujeto y modernidad.400 años de las Novelas Ejemplares. Grupo de Estudios Cervantinos, Facultad de Humanidades y Ciencias de la Educación (Udelar), Montevideo, 2014, pp. 19-33.

22 El excelente trabajo de Figueredo, titulado Viday obra de Miguel de Cervantes Saavedra, fue publicado por la Comisión de Cultura de Pan de Azúcar y la Comisión pro-edición de las obras de Álvaro Figueredo, con el apoyo de la Intendencia de Maldonado, 1986. 
Cuando escribió esta novela había comprendido de una vez por todas que el destino del mundo ya no se jugaba en el mar Mediterráneo. En algún momento llamó a Lepanto: «la más memorable y alta ocasión que vieron los pasados siglos ni esperan ver los venideros ${ }^{23}$ y se equivocó de medio a medio. Si no fuese porque Cervantes perdió allí el uso de su brazo izquierdo no sabríamos nosotros, probablemente, nada sobre aquella batalla que a lo sumo tuvo un valor simbólico del enfrentamiento de Europa con el Imperio Turco. En el Persiles intuyó correctamente Cervantes, ahora sí, que el Atlántico era el nuevo escenario de la historia. Los dos primeros libros son el testimonio asombrado de esta nueva realidad, y el interés de esta mitad de la obra queda asegurado, siquiera, porque ella es el documento de cómo Cervantes, espíritu sensible y privilegiado, adivinaba el futuro inminente en aquellos tiempos augurales.

Todo esto consagra al Persiles, además, como la novela del mar, en tanto el Quijote es la novela de tierra adentro. Don Quijote y Sancho no navegan jamás, salvo en una grotesca aventura que los pone sobre una barca en el Ebro. El caballero pregunta al escudero si se le han muerto los piojos, porque se decía que al cruzar el Ecuador era el calor tan infernal que ningún bichito sobrevivía, por voraz que fuese. Don Quijote y Sancho ven por fin el mar, en Barcelona: el Mediterráneo, el mar interior, el que media entre tierras próximas. La escena es famosa: viendo cómo se mueve una galera con aquellos pies entrando al agua que se le figuran los remos, Sancho descubre que «éstas sí son cosas de encantamiento y no las que mi amo dice». ${ }^{24}$

De modo bien diferente, el Persiles recoge la experiencia de Cervantes marinero. Sabe que todo va bien si el agua de la sentina está sucia y hedionda: no ha entrado agua nueva. Sabe que los vinos mejoran en las travesías largas. Pero sabe el mar, además, por los ojos, los oídos y el olfato, huele sus aromas y ve y escucha las superficies siempre cambiantes. Azorín fue singularmente sensible a este aspecto del Persiles. Él se suma a la identificación del océano con el misterio. La Odisea, con su atmósfera épica, está quizá detrás de algún lance asombroso: «vi alzar y poner en el navío un cuello como de serpiente terrible, que, arrebatando a un marinero, se le engulló y tragó de improviso, sin tener necesidad de mascarlo». ${ }^{25}$ Pero frecuentemente son sólo las olas blancas de espuma, las playas, el atardecer sobre el mar, el horizonte infinito, las brisas saladas.

\footnotetext{
23 Miguel de Cervantes: Prólogo. En: Novelas Ejemplares. Juan Bautista Avalle Arce (ed.). Castalia, Madrid, 1982.

${ }^{24}$ Miguel de Cervantes: Quijote.

25 Miguel de Cervantes: Los trabajos de Persiles y Sigismunda, II, XVI.
} 
Volvamos en fin, todavía, a la otra gran avenida de acceso a la novela: su estructura. Es, en realidad, un conglomerado de relatos cortos que se insertan, progresivamente, en la acción principal. Todos los personajes que se cruzan con Periandro y Auristela -por así decir- aportan sus variadas historias personales, de modo que la general contiene una casi ilimitada cantidad de pequeñas novelas. El todo confirma que Cervantes es un maestro de la narración breve y que su «tiro» habitual es, por ejemplo, la novela ejemplar, o las intercaladas en el Quijote. El relato de «tiro» largo es él mismo desmontable en relatos breves, como lo verifica la composición del Quijote, cuyas partes pueden ser leídas con independencia las unas de las otras, tal como las leen, por ejemplo, alumnos y profesores de la enseñanza media en el Uruguay y en cualquier otro país.

El Persiles no difiere demasiado, en esto, del Quijote. Difiere, sí, en que aquí no hay aventuras; hay trabajos. Hay el empeño de la voluntad para vencer un obstáculo que objetivamente se presenta, no la provocación de algo que tantas veces no existe como obstáculo y que don Quijote crea como tal en su imaginación: los mercaderes como enemigos, por ejemplo, o los gigantes en que se han convertido los molinos. También hay aquí un viaje distinto, porque en tanto en el Quijote se viaja para cualquier lado, aquí se va a Roma. $\mathrm{El}$ peregrino ha sustituido al andante, de modo que una finalidad ordena y modifica a la búsqueda errática. Cervantes parece corregirse a sí mismo, o sustituir al héroe en broma por el héroe verdadero.

\section{Mensajes, etimologías, símbolos}

El motivo permanente y central del viaje a Roma ha sostenido el entusiasmo de quienes ven en Cervantes a un abanderado de la Contrarreforma. Según algunos lectores, habría sido un defensor del Concilio de Trento y un espíritu que, por su rigor e intransigencia, calificaríamos hoy de reaccionario. El modelo de esta interpretación es el alemán Julius Klein, quien veía en Cervantes a «una salamandra tan inquisicionófila» ${ }^{26}$ como Lope o Calderón. Lo que sigue procurará mostrar que estos fervores deberían enfriarse. En su posición frente a Roma y en el momento tan polémico del cisma, que

\footnotetext{
${ }^{26}$ Julius KLein. Citado por Américo Castro en Elpensamiento de Cervantes. Noguer, Barcelona-Madrid, 1980.
} 
dividió apasionadamente al cristianismo europeo, Cervantes fue -como en todo- un moderado y alguien que, por su audacia de librepensador en algunos asuntos capitales, aparece como un espíritu moderno. La discusión sobre estos aspectos debe pasar necesariamente por el Persiles. Ella invita a complementar la lectura que se entrega al goce del libro de entretenimiento -designación que asumía el propio Cervantes- y considerar la otra dimensión posible de la novela: la que acepta que en ella se esconde el mensaje de Cervantes sobre grandes cosas, las mismas que le preocupaban a la hora de librar a la imprenta su testamento literario.

Esta lectura exige del lector mucho más que una actitud pasiva: solicita una disposición y hasta una preparación mayor que la reclamada por cualquier otra obra de Cervantes. Vale la pena copiar unas palabras de Menéndez Pelayo, del discurso leído en la Academia el 29 de mayo de 1904. Hemos quitado fragmentos neutros para nuestro propósito y todo lo hemos extractado y unido según convenía a él. Dice el polígrafo español:

¿Quién sabe si el cervantismo simbólico será una especie de alquimia que prepare y anuncie el advenimiento de la verdadera química? El Quijote habla a la humanidad de todos los tiempos no por alegorías y enigmas, sino con la voz llana y persuasiva de la sabiduría práctica encarnada en tipos inmortales. Tienen razón los que afirman que no hay sentido oculto en el Quijote, que todo es diáfano en el pensamiento y estilo de la sabrosa fábula. ${ }^{27}$

Y pasa luego a encarecer las enseñanzas «no veladas, ni en cifra, ni puestas allí en forma de acertijo, que el lector atento puede extraer del «progreso orgánico» de la historia». ${ }^{28}$

Si trasladamos estas reflexiones al caso del Persiles, podremos reconocer que también allí hay lecciones no encubiertas, sino indisociables de la historia contada. Pero el lugar de la «alquimia», el acertijo y el enigma, es considerablemente mayor ahora. El Persiles no es, en este plano, el Quijote: la alegoría se superpone frecuentemente al trabajo del escritor transparente, que parece empeñarse ahora en desafiar a su lector, retándolo para que acceda por sí mismo a los significados secretos. Pero esta complicidad entre Cervantes

\footnotetext{
27 Marcelino Menéndez Pelayo: Interpretaciones del Quijote (Discurso leído en la Real Academia Española, en 29 de marzo de 1904, contestando al de recepción de don José María Asensio) en: Interpretaciones del Quijote. Edición nacional de las obras completas de Menéndez Pelayo VI Estudios y discursos de crítica histórica y literaria I, Santander 1941, p. 313.

28 Marcelino Menéndez Pelayo: Interpretaciones del Quijote, p.315.
} 
y nosotros difícilmente pueda reducirse a considerar a la novela como un mensaje al fin simple, y que remite siempre al drama de la salvación según el sentir católico del barroco.

Los mayores defensores de esta lectura han sido Helmut Hatzfeld ${ }^{29}$ y Joaquín de Casalduero. El mérito del conocido libro de este último -Sentido y forma de Los trabajos de Persiles y Sigismunda- ha sido el esfuerzo por hallar una interpretación coherente y totalizadora, ordenada y sistemática, capaz de explicar todos los aspectos de una novela casi caótica, por momentos, en el bailoteo que sacude a los personajes como verdaderas marionetas. A veces siente el lector que Casalduero se pierde por cartas de más, pues todo -absolutamente todo- pasa a funcionar alegóricamente, como si Cervantes no se hubiera distraído nunca para dejar correr a su pluma ágil y suelta y a su imaginación despejada. Así, si Periandro sale de una mazmorra y busca encandilado la luz del sol, he aquí la alegoría de la ansiedad de Dios en el hombre perdido. Cervantes no ha contado nada que no sea ejemplo para una enseñanza moral y religiosa, y en todo ha tenido en cuenta la contraposición -de la Contrarreforma y del propio Casalduero- entre el hombre natural, un bárbaro, y el hombre modelado según la doctrina cristiana.

La fidelidad absoluta a este tipo de lectura - a un sistema, a un método invariable-conduce, en fin, a resultados sorprendentes. Se lee, por ejemplo, cuando se explica el enlace barroco de lo real y los arquetipos: «Un hombre barroco (y ahora no voy a señalar la diferencia entre esa época y el Renacimiento), para gozarse en la contemplación del cuerpo desnudo elevará a la mujer hasta Venus». ${ }^{30}$ Cuesta imaginar a quienes sorprendieron a aquella muchacha de La señora Cornelia completamente desnuda cuando cayó por accidente la sábana que la envolvía, complacerse sólo después de haber evocado a Afrodita. Si alguien disfruta de tiempo ocioso, puede entretenerse imaginando las torcidas y traslaticias lujurias del hombre barroco. Todo esto huele demasiado a ideología; vale decir, a discurso sin variante posible, y en consecuencia ciego para la realidad dialéctica de las cosas humanas y artísticas. El resultado, por añadidura, no parece demasiado original ni demasiado rico, ya que el crítico termina encerrando el sentido general de la novela en la siguiente piedra de toque: «En la nave de la vida, por el mar del mundo,

\footnotetext{
${ }^{29}$ El trabajo más importante de Hatzfeld sobre Cervantes es: El Quijote como obra de arte del lenguaje. Madrid, Consejo Superior de Investigaciones Científicas, 1966.

30 Joaquín de CASAlduero: Sentido y forma...
} 
guiados por la honestidad, aquilatarse en la firmeza y la lealtad, que nos conducen al puerto quieto». ${ }^{31}$

En la visión de Casalduero, desde luego, es primordial tener en cuenta que el final del viaje es Roma, cabeza de la Contrarreforma. Persiles, figuración de Cristo, y Sigismunda, la Iglesia, van hacia el Pontificado. Pero también esta lectura es parcial y un poco falsa, pues el verdadero fin del viaje -como está insistentemente declarado en el texto mismo de la novela- no es Roma sino Tule. Hasta podría conjeturarse que, si Cervantes no contó lo que sería el desenlace natural de la historia, fue por la prisa con que concluyó la redacción de ella. Todo el mundo la ha reconocido en el libro cuarto, el más breve de todos, y tanta ansiedad tal vez se deba simplemente a que se sentía morir. Cabe consignar el final razonablemente previsible: con lo aprendido en Roma, la pareja vuelve a un reino en los confines de la tierra donde se establecerá, por fin, la ciudad de Dios. La novela discutiría, así, la jerarquía de Roma, cuya corrupción está abundantemente señalada en el Persiles. Esta lectura se confirma si se tiene en cuenta que el más asiduo peregrino a Roma, y que acompaña a Persiles y Sigismunda a lo largo de varios capítulos, se llama Rutilio. Si aceptamos el juego de etimologías crípticas y de sentido sin embargo transparente, el personaje representaría un «rutilar»: una fe más brillante que sólida, una bella luz -como Luzbel al fin-pero que quizá no sale desde dentro aunque luzca bien afuera. El asunto del viaje a Roma no debería dejar de lado, por otra parte, a los dos naufragios narrados en el Persiles, y en los cuales se suele reconocer la alusión a los dos cismas: el de Aviñón y el que separó a católicos y protestantes, en un conflicto de cuyas consecuencias fue Cervantes, precisamente, testigo ilustrado.

La mención de Rutilio, y de las interpretaciones fundadas en los nombres elegidos para los personajes, vuelve necesaria ahora una referencia a Cecilio Peña, el uruguayo que mejor ha escrito sobre el Persiles. Se dirá, con toda justicia, que quien esto escribe no puede juzgar a Cecilio, pues fue su amigo y hasta publicó con él, hace muchos años, el volumen Persiles. ${ }^{32}$ Aquel librito contenía dos trabajos: Presentación del Persiles, de Cecilio Peña, y Cervantes y el Persiles, del suscrito, estudio este último en el que aparecían ya algunas de las ideas ahora aquí desarrolladas. Pero Peña siguió trabajando luego denodadamente sobre la novela: solo y soñando siempre contar con el

\footnotetext{
31 Joaquín de Casalduero: Sentido y forma...

32 Jorge Albistur y Cecilio Peña Martín: Persiles. Cuaderno de Literatura No 35. Fundación de Cultura Universitaria, Montevideo, 1977.
} 
equipo multidisciplinario que le ayudara en las alusiones históricas que su investigación iba revelando y tanto enriquecían su visión del relato. El resultado, siempre provisorio, de su trabajo, apareció en la revista Asomante, de Puerto Rico ${ }^{33}$ y finalmente en Hacia el sentido del Persiles, librito de edición del autor y desamparado de cualquier repercusión verdadera, más allá de un reducidísimo grupo de lectores y los asistentes a una charla en la Cátedra «Alicia Goyena» de Educación Secundaria. ${ }^{34}$ Guido Castillo, que fue nuestro profesor de Literatura Española -de Cecilio y de mí mismo- ya no estaba en el país, y nuestra ignorancia de lo que se hacía y se escribía en España era, por entonces, mucho más grande que la de ahora, pues no existía el actual maravilloso mundo de las comunicaciones electrónicas.

Confiado en que los nombres -Quijote, Rocinante, Dulcinea- esconden en Cervantes enormes valencias significativas, Cecilio Peña descubrió que Constanza, hija de Antonio el español y Ricla la bárbara, y compañera en el viaje de Sigismunda, es tal vez el símbolo del Concilio de Constanza, de 1415. Allí se consideró la aspiración de reunir en una sola a todas las Iglesias, con una amplitud que iba más allá de cualquier cisma concebible. Peña destaca, además, que el emperador Sigismundo fue quien convocó el Concilio de Constanza.

Tal vez no esté de más advertir que nuestro amigo leía el Persiles a través de Bataillon ${ }^{35}$ y Guignebert ${ }^{36}$ y proponía otras identificaciones: la de Seráfido, ayo de Persiles, con San Francisco de Asís, por ejemplo. Pero tal vez ninguna tan importante como la que vuelve a Maximino, el hermano de Persiles, en el símbolo del Antiguo Testamento. Este personaje llega también a Roma, aunque detrás de Persiles y siguiendo otro camino, y apenas pisa la ciudad sufre la «mutación». Así se llamaba una enfermedad frecuente entre quienes visitaban Roma en verano, pero acaso se aluda a la mudanza del Antiguo en Nuevo Testamento: una mudanza feliz, porque Maximino une a los amantes y muere.

Cecilio Peña apostaba a estas lecturas audaces y fue consciente, al mismo tiempo, de hasta dónde eran ellas endebles y polémicas. Sea como fuere, tienen la ventaja de unificar la imagen de Cervantes y no dividirla en los rostros inexplicablemente distintos de dos hombres diferentes: el uno autor

\footnotetext{
33 Cecilio Peña Martín: En el último mundo cervantino. En: Asomante, nº 4, San Juan de Puerto Rico, 1962, pp. 61-68.

34 Cecilio Peña Martín: Hacia el sentido del Persiles. Cecilio Peña, Montevideo, 1988.

35 Marcel Batalllon: Erasmo y España. Fondo de Cultura Económica, México, 1950.

36 Leído tal vez en la versión francesa de 1922, pues Cecilio comprendía sin dificultades esta lengua. No conozco traducción al español del libro de Guignebert El cristianismo medievaly moderno.
} 
del Quijote y otros textos propios de un librepensador y el otro vuelto de pronto ortodoxo a ultranza. El Persiles confirmaría al Quijote, y Cervantes seguiría siendo el mayor erasmista español de los Siglos de Oro, tal como lo vieron Marcel Bataillon y Américo Castro. ${ }^{37}$ Su erasmismo iba mucho más allá de la influencia de El elogio de la locura sobre el Quijote y Cervantes habría abogado por un encuentro personal con Dios, ayudado por la menor cantidad posible de dogmas y desconfiado de los cultos públicos y la condición sacerdotal. El entremés de El viejo celoso, por ejemplo, sería una ilustración humorística del «monacatus non est pietas» de Erasmo: un ataque liso y llano a ciertas personalidades tonsuradas.

En un país sin protestantismo, como fue España, Erasmo ocupó un lugar central en la historia de las ideas. Como ha dicho Hauser, entre otros, tenía una suavidad distinta del agresivo Lutero, y quizá por eso mismo resultó más peligroso para la Iglesia conservadora. ${ }^{38}$ Su estilo calmo sostenía una cruzada persuasiva y paciente. En un gesto absolutamente simbólico -y el simbolismo lo aporta ahora la realidad, y no el arte- fue Rodrigo Manrique quien firmó la autorización para que El elogio de la locura pudiera leerse en España. El buen hombre era el hermano menor de Jorge Manrique, un poeta que representa íntegramente al espíritu medieval y que a título de tal se ha enseñado siempre en nuestros cursos liceales de Literatura, por ejemplo. La vieja España le dejaba así un sitio a los voceros de la modernidad incipiente.

Fue el protestantismo, ya no Erasmo, quien enseñó que la salvación era obra de la Gracia, y no el resultado de las buenas obras humanas. Lutero decía sibilinamente: si la salvación depende de las buenas obras, un hombre que ha obrado bien se asegura y encadena la voluntad de Dios, suprimiendo la libertad de éste. Dios no puede sino salvarlo. Este extremo es imposible. Dios hace lo que quiere y por eso es libre. El espesor de un dios misteriosamente arbitrario se cernía sobre los conceptos tranquilizadores. Dios -la Graciaes quizá lo que no se puede comprender: lo absolutamente Otro, como vendrá a decir Kierkegaard tanto tiempo después. No sabemos qué pudo pensar Cervantes de todo esto y ni siquiera si comprendió el alcance de las nuevas ideas. Llama la atención -eso sí- que él no tuviera problema alguno con la Inquisición cuando denunció a la justicia española por sus espantosas torturas, en el episodio de los galeotes ${ }^{39}$ o puso en tela de juicio, en el mismo

\footnotetext{
${ }^{37}$ Fundamentalmente en: Américo Castro: El pensamiento de Cervantes, pero también en: Américo Castro: De la edad conflictiva. Taurus, Madrid, 1961.

38 Cfr. Arnold Hauser: El manierismo, crisis del renacimiento. Guadarrama, Madrid, 1971.

39 Miguel de Cervantes: Quijote, Primera Parte, capítulo xxiI.
} 
pasaje, que el rey pudiese condenar a alguna gente. Todo esto y más le toleró la Inquisición. Pero le borró esta frase del Quijote, desde luego recuperada en las ediciones modernas: «Las obras de caridad que se hacen tibia y flojamente no tienen mérito ni valen nada». ${ }^{40}$ Era demasiado. La frase olía de lejos a protestantismo. La salvación consistía en portarse bien, y la Iglesia era la institución que discernía sabiamente cuáles eran las conductas correctas y las censurables. Meterse a considerar si las conductas eran o no flojas, y si tenían mérito, era imposible. Para que todo fuese manejable era imprescindible sostener un código objetivo.

\section{El naufragio feliz}

Si hubiera en el Persiles este o cualquier otro sistema de ideas, él tendría que ser compatible con la organización aparentemente caótica de la novela bizantina, que tan bien se avenía, por lo demás, al temperamento de Cervantes. Su instinto de artista le enseñaba a reconocer las virtudes de lo simple, pero tenía la pasión irrefrenable de contar y, con la facilidad alegre que siempre se le ha elogiado, inventaba una y otra historia, con ingenio poderoso y desordenado. Cervantes trabaja siempre con exceso de materiales y quizá por eso le atrajo la novela bizantina. Menéndez Pelayo sentenció que ella suplía a los personajes y la acción, borrosos, con el hacinamiento de aventuras extravagantes. Y, si en el Quijote pide Cide Hamete «que se le den alabanzas no por lo que escribe, sino por lo que ha dejado de escribir», ${ }^{41}$ no faltan en el Persiles disculpas parecidas, que muestran a Cervantes preocupado por su derroche en la invención. Se lee por ejemplo, apenas comenzado el Segundo Libro: «Parece que el volcar de la nave volcó, o, por mejor decir, turbó el juicio del autor de esta historia, porque a este segundo capítulo le dio cuatro o cinco principios, casi como dudando qué fin en él tomaría.$^{42}$ Los hilos de la maraña amenazan con dejar preso entre sus redes al propio creador, siempre preocupado sin embargo por «el galán progreso de esta historia» (31). ${ }^{43}$ Uno de los recursos a que más frecuentemente echa mano para defender las

\footnotetext{
40 Miguel de Cervantes: Quijote, Segunda Parte, capítulo XXXVI.

${ }^{41}$ Miguel de Cervantes: Quijote, Segunda Parte, capítulo XLIV.

${ }^{42}$ Miguel de Cervantes: Los trabajos de Persiles y Segismunda, II, II.

${ }^{43}$ Miguel de Cervantes: Los trabajos de Persiles y Segismunda IV, VIII.
} 
confusas digresiones es atribuirlas al «autor de esta historia»: ${ }^{44}$ un imaginario escritor a quien, como a Cide Hamete en el Quijote, dice traducir. En algunos casos parece que escucháramos al Cervantes del Quijote mismo:

Parece que el autor de esta historia sabía más de enamorado que de historiador, porque casi este primer capítulo de la entrada del Segundo Libro lo gasta todo en una definición de celos ocasionada de los que mostró tener Auristela por lo que le contó el capitán de navío; pero en esta traducción, que lo es, se quita por prolija, y por cosa en muchas partes referida y ventilada, y se viene a la verdad del caso. ${ }^{45}$

Así como don Quijote y Sancho ejercen un efecto de imán sobre innumerables transeúntes de las rutas manchegas, que se agregan al desatinado viaje, así también Persiles y Sigismunda arrastran tras de ellos a todo un ejército de acompañantes, cada uno de los cuales cuenta su historia. Elegir un único episodio en esta abundancia no tiene mayor sentido. Se hará aquí, sin embargo, para mostrar cómo se proyectan desde y hacia un pasaje puntual los lineamientos generales que explican la novela.

El fragmento elegido es el encuentro de Periandro y Auristela con Antonio de Villaseñor y Ricla, la salvaje a quien convirtió en su esposa: ${ }^{46}$ un desarrollo inolvidable para lectores americanos del Persiles, pues el escenario es indudablemente América tal como la imaginaba Cervantes. Ésta sola sería una muy buena razón para explicar la elección que aquí se hace. Se verá, además, hasta dónde se recogen aquí las ideas-fuerza del erasmismo.

En el pasaje en cuestión siempre se ha reconocido la influencia del Inca Garcilaso de la Vega: una influencia más o menos atmosférica, por decir así, pues Cervantes leyó con gran interés los Comentarios reales, y una influencia perfectamente puntual, ya que Cervantes recrea el suceso de Pedro Serrano, náufrago que vivió tres años, solo, en una isla cercana al Perú, y que el Inca cuenta en el capítulo viII de la Primera Parte de su libro. El entusiasmo de Cervantes con la obra del Inca es, por otra parte, un acontecimiento lleno de significación y que revela la distancia que él tomaba de aquello que la Corona pensaba a propósito del libro: la monarquía lo vio siempre como peligroso, pues había allí demasiada nostalgia de la América anterior a la conquista

\footnotetext{
44 Miguel de Cervantes: Los trabajos de Persiles y Segismunda II, I.

45 Miguel de Cervantes: Los trabajos de Persiles y Segismunda II, I.

46 Miguel de Cervantes: Los trabajos de Persiles y Segismunda, I, IV y ss.
} 
española, y al fin, en pleno siglo XVIII, formalizó su descontento y su temor. En 1781, en efecto, por Real Cédula, se prohibió la difusión de los Comentarios reales, porque los indios podían aprender allí «muchas cosas inconvenientes». Después del alzamiento de Tupac Amaru, el Inca Garcilaso se convirtió en una lectura francamente subversiva y su libro sólo se reeditó gracias a una suscripción organizada por el general José de San Martín. ¿Cabe pensar en un módico hecho editorial más cargado de simbolismo?

Es curioso cómo el destino parece haberse empeñado en relacionar dos vidas tan distintas como las de Cervantes y el Inca. Éste murió el 22 de abril de 1616, un día antes que el autor del Quijote. Era hijo de una nieta del Inca Yupanqui y su padre era pariente del poeta español del Renacimiento. En aquella España impiadosa en cuanto a la impureza étnica -dividida en «castas», como dice Américo Castro ${ }^{47}$ - el Inca era declaradamente mestizo; tanto, que decía de este nombre: «me lo llamo a boca llena y me honro con él». Para mayor relación con Cervantes, aunque ésta meramente accidental, el padrino de bautismo del Inca fue don Diego de Silva, hijo de Feliciano de Silva, aquel que escribiera «la razón de la sinrazón que a mi razón se hace», la frase que sale en el Quijote como ejemplo de un estilo maldito.

De este hombre tomó Cervantes muchos elementos para la historia de Antonio el español, esa especie de Robinson Crusoe del Persiles que naufraga y se refugia en una cueva donde habrá de conocer a Ricla. La crítica ha señalado las similitudes con el relato del Inca. Son ellas el vestir pieles, la unión de tablas para fabricar balsas o puentes flotantes, el conocimiento de la diferencia entre plantas venenosas y bienhechoras, brujerías varias y el encendimiento del fuego frotando palos y piedras: un asunto este último familiar hoy en innumerables relatos de aventuras pero absolutamente novedoso en tiempos de Cervantes.

El propio Antonio traza su retrato, en el que habrá de apreciarse el gran estilo culto de Cervantes. Dice este personaje: «Llegué a las puertas de la Gramática, que son aquellas por donde se entra a las demás ciencias; inclinóme mi estrella, si bien en parte a las letras, mucho más a las armas; no tuve amistad en mis verdes años ni con Ceres ni con Baco, y así en mí siempre estuvo Venus fría». ${ }^{48}$ Son escasos o nulos los puentes que puedan tenderse entre este lenguaje y el habla cotidiana: el secreto de este estilo está en las estudiadas equivalencias sintácticas, los ritmos uniformes y la respiración

\footnotetext{
47 Cfr. Américo Castro: La realidad bistórica de España. Editorial Porrúa, México, 1954 (e importante reedición, con agregados, en 1965).

48 Miguel de Cervantes: Los trabajos de Persiles y Segismunda, I, V.
} 
apacible, el nervio sometido a disciplina elegante, las alusiones a todo un riquísimo mundo cultural que apela, por añadidura, a los símbolos del mejor clasicismo. Decretar que todas estas virtudes hacen al Persiles superior al Quijote en materia de estilo resulta, sin embargo, peligrosamente arbitrario si se acepta que el estilo representa, más allá de la superficie lingüística, a la complejidad de todo un plan y una ejecución novelesca. El Quijote es inigualable en la frescura y el vigor del lenguaje popular, en un humorismo y una ironía que Cervantes no repitió jamás. En el Persiles cuenta con una veloz acumulación de acciones todas perfectamente ordenadas en la sucesión, como si quisiese organizar, en el interior de las frases, el caos que amenaza constantemente al total. Véase este ejemplo del vértigo pero sujeto a norma:

Entré en la barca con sólo dos remos; alargóse la nave; vino la noche oscura; hálleme solo a la mitad de la inmensidad de aquellas aguas sin tomar otro camino que aquel que le concedía el no contrastar contra las olas ni contra el viento; alcé los ojos al cielo; encomendéme a Dios con la mayor devoción que pude; miré al Norte, por donde distinguí el camino que hacía, pero no supe el paraje en que estaba. ${ }^{49}$

Cuenta luego Antonio cómo llegó hasta una cueva donde protegerse y cómo soñó allí con un lobo que le hablaba. Casalduero no duda, y probablemente acierta, cuando relaciona a este lobo con tantos otros animales del bestiario alegórico medieval, sin olvidar a la loba dantesca: el lobo es la depravación que habla para tentar a este hombre perdido y angustiado. Pero después apunta el crítico, llevado por su permanente intención de ver en Cervantes al ultra-católico, que Antonio representa a la Iglesia primitiva refugiada en las catacumbas. Le parece, por extensión o similitud, que todo el episodio es imagen de la Contrarreforma rodeada por «las fieras y la barbarie del protestantismo». En torno hay, sí, peligros, pero también está Ricla, que ayuda a Antonio el español y termina convirtiéndose en su esposa.

La presentación de la muchacha introduce en el episodio un aire que hoy podemos llamar «rousseauniano», añadiendo que Cervantes parece adivinar esa sensibilidad todavía tan lejana. Ricla —«una muchacha bárbara, de hasta edad de quince años»- recoge mariscos, pero por la sorpresa de ver al desconocido se le caen todos los frutos del mar que había encontrado. Antonio le besa las manos y le transmite, como puede y por señas, sus buenas

\footnotetext{
49 Miguel de Cervantes: Los trabajos de Persiles y Segismunda, I, V.
} 
intenciones. «Ella, pasado aquel primer espanto, con atentísimos ojos me estuvo mirando, y con las manos me tocaba todo el cuerpo, y de cuando en cuando, ya perdido el miedo, se reía y me abrazaba». ${ }^{50}$

El episodio es rousseauniano no ya por el paisaje, paradisíaco lugar para una nueva sociedad sin perversiones y que no ha dañado todavía al hombre. Es también rousseauniano por la concepción misma de la criatura humana, que para nada está vista según la sentencia bíblica: aquí, el hombre no es de mala levadura. Por el contrario, las almas vírgenes son el bien, tal como las juzgó Rousseau en el romanticismo y Erasmo en los tiempos de Cervantes. ${ }^{51}$ Por eso, Ricla se descubre a sí misma y empieza a conocerse con una sonrisa. Lejos de condenar el deseo de entrega que nace poco a poco en ella, lo consiente sin miedo y sin verlo jamás como el mal.

En cuanto a Antonio, el español entre bárbaros, conviene comparar este relato con tantos otros de las crónicas de Indias, para apreciar cómo imaginaba o deseaba Cervantes el encuentro con seres tan diferentes e ignorantes de la fe católica. Michele de Cúneo, lugarteniente de Colón, recibió del Almirante el obsequio de una «caníbal». La mantuvo días en el camarote, desnuda y sometida a latigazos. Ella quedó al fin tan condescendiente, «que parecía amaestrada en una escuela de putas». ${ }^{52}$ Antonio, el español de Cervantes, enseñó a Ricla su lengua y -asunto fundamental- aprendió también la que ella hablaba, con el fin de explicarle luego cuál era su fe.

Después de todo este proceso, Antonio y Ricla se conceden mutuamente el sacramento del matrimonio y Cervantes - erasmista en esto de modo desembozado-aprueba y aun celebra este matrimonio sin sacerdote ni Iglesia que lo validen, en una actitud insólita en la España de los Austria. ${ }^{53}$ Lo que en estos pasajes sucede es inconcebible en Lope, por ejemplo, que era familiar de la Inquisición, y también en Quevedo, aunque él intentaba conciliar una teoría política reaccionaria con su auténtico amor por los desheredados. ¿Cabe sostener, todavía, que Cervantes es un representante, en las letras, de la Contrarreforma? ¿No será que esta visión se refuta sola, apenas se lee sin prejuicios el Quijote, el Persiles o cualquiera otra de sus páginas?

50 Miguel de Cervantes: Los trabajos de Persiles y Segismunda, I, VI.

51 Sobre la concepción del hombre naturalmente bueno en los escritos de Erasmo, subraya Américo Castro, en El pensamiento de Cervantes, el coloquio De puris instituendis.

52 Michele de Cúneo. Carta del 15-28 de octubre de 1495. En: Floresta de Indias. Alberto M. Salas y Miguel A. Guerin (eds.). Losada, Buenos Aires, 1970.

53 También sin sacerdote se casan, en Persiles III, XXI, Isabela Castrucho y Andrea Marulo: «Tomó la mano de Isabela y ella le dio la suya, y con dos síes, quedaron indubitablemente casados». "¿Y Trento?», se pregunta Américo Castro, otra vez en Elpensamiento de Cervantes. 
Ajeno a la Contrarreforma y vocero temprano de la modernidad, creyó Cervantes, en el Persiles como en el Quijote, en un ser que es antes que nada un querer ser; un ser que es casi solamente una elección de sí mismo. Periandro y Auristela quieren ser Persiles y Sigismunda, como Alonso Quijano quiere ser don Quijote de la Mancha. Y en tanto Periandro y Auristela son cada vez más Persiles y Sigismunda, don Quijote va siendo cada vez menos el caballero andante, hasta que al fin deja de serlo. Los seres pueden ser o dejar de ser y por eso Sancho, además, renuncia a ser gobernador y retorna al escudero, que por otra parte era íntimamente tan solo un labrador.

La realidad también es, en Cervantes, algo inestable, que se refracta en un prisma; vale decir, en innumerables puntos de vista. Cervantes había leído bien a Erasmo, que decía en El elogio de la locura: «La realidad de las cosas depende sólo de la opinión. Todo en la vida es tan oscuro, tan diverso, tan opuesto, que no podemos asegurarnos de ninguna verdad»r. ${ }^{54}$ Baltasar Castiglione, el autor de aquel libro llamado El cortesano, tan leído por Cervantes y su tiempo, agregaba este otro comentario de sustancia erasmista: «No solamente a vos puede parecer una cosa y a mí otra, sino que a mí mismo podría hoy parecer una cosa y en otra hora, otra». ${ }^{55}$

¿Cómo se sintetiza el ser, en esta ubicua inestabilidad? Procura hacerlo, ya modernamente, en el instante total, aquel simulacro que ilusoriamente ofrece la plenitud deseada. Así Policarpo, en el Persiles, ${ }^{56}$ pierde su reino porque prefiere poseer a la mujer que ama y Ruperta -en otro instante total del amor- va en la noche en busca del hombre al que piensa asesinar pero termina acostándose con él. ${ }^{57} \mathrm{El}$ instante es shakespeariano, es dostoievskiano también, y el ser no se acomoda a ningún sistema, a ninguna filosofía que pueda mantenerlo coherente y siempre igual a sí mismo.

La otra síntesis, desde luego, es la hora de la muerte. Se conmemoraron en 2016 los cuatrocientos años del fin de Cervantes, y el Persiles contiene, en la Dedicatoria y el Prólogo, la despedida de Cervantes. El 19 de abril, cuatro días antes de la muerte, le escribía al conde de Lemos:

\footnotetext{
54 Erasmo de Rotterdam. Elogio de la locura. Aguilar. Barcelona, 2007.

55 Baltasar Castiglione. El cortesano. Alianza, Madrid, 2008.

56 Miguel de Cervantes: Los trabajos de Persiles y Segismunda, II, V y ss.

${ }^{57}$ Miguel de Cervantes: Los trabajos de Persiles y Segismunda, III, XVII.
} 
Aquellas coplas antiguas, que fueron en su tiempo celebradas, que comienzan

\section{Puesto ya el pie en el estribo}

quisiera yo no vinieran tan a pelo en ésta mi epístola, porque casi con las mismas palabras las puedo comenzar diciendo:

\section{Puesto ya el pie en el estribo, con las ansias de la muerte gran señor, ésta te escribo.}

Ayer me dieron la Extremaunción, y hoy escribo ésta: el tiempo es breve, las ansias crecen, las esperanzas menguan, y, con todo esto, llevo la vida sobre el deseo que tengo de vivir, y quisiera yo ponerle coto hasta besar los pies de vuestra excelencia bueno en España, que me volviese a dar la vida. Pero si está decretado que la haya de perder, cúmplase la voluntad de los cielos. ${ }^{58}$

Y en el Prólogo, seguramente de esos mismos días finales, se dirige a todos los lectores y les dice: «Tiempo vendrá, quizá, donde, anudando este roto hilo, diga lo que aquí me falta y lo que sé convenía. ¡Adiós gracias, adiós donaires, adiós, regocijados amigos; que yo me voy muriendo, y deseando veros presto contentos en la otra vida!». ${ }^{59}$

Ya importan poco sus obras, o las interminables polémicas, muchas veces innobles, con otros escritores envidiosos de su después de todo no muy agraciada fortuna. Ya casi nada importa y las páginas tienen ese tono lejano, un poco ausente aunque siempre irónico, que Cervantes refiere ahora a una tentativa de síntesis de sí mismo. Por entonces había vivido demasiadas cosas para enaltecerse y demasiadas para humillarse; demasiadas para sentirse feliz y demasiadas para sentirse desgraciado; sabía demasiadas cosas para amar y demasiadas cosas para odiar. La síntesis era una especie de regreso al todo y a la simplicidad primera.

\footnotetext{
58 Miguel de Cervantes: Los trabajos de Persiles y Segismunda, Dedicatoria.

59 Miguel de Cervantes: Los trabajos de Persiles y Segismunda, Prólogo.
} 


\section{Bibliografía}

Albistur, Jorge: Las Ejemplares: «mostrar con propiedad un desatino». En: María de los Ángeles GonzÁLEz Briz (ed.): Barroco, sujeto y modernidad. 400 años de las Novelas Ejemplares. Grupo de Estudios Cervantinos, Facultad de Humanidades y Ciencias de la Educación (UDELAR). Montevideo, 2014, pp. 19-33.

Albistur, Jorge: Cervantes y América. En: Cuadernos hispanoamericanos, $\mathrm{n}^{\circ} 463$, Madrid, 1989, pp. 65-72.

Albistur, Jorge y Cecilio Peña Martín: Persiles. Cuaderno de Literatura $\mathrm{N}^{\circ} 35$. Fundación de Cultura Universitaria, Montevideo, 1977.

Azorín: Al margen de los clásicos. Losada, Buenos Aires, 1942.

Bataillon, Marcel: Erasmo y España. Fondo de Cultura Económica, México, 1950.

Casalduero, Joaquín de: Sentido y forma de Los trabajos de Persiles y Sigismunda. Gredos, Madrid, 1975.

Castiglione, Baltasar: El cortesano. Alianza, Madrid, 2008.

Castro, Américo: El pensamiento de Cervantes. Noguer, Barcelona-Madrid, 1980.

Castro, Américo: De la edad conflictiva. Taurus, Madrid, 1961.

Castro, Américo: Hacia Cervantes. Taurus, Madrid, 1957.

Castro, Américo: La realidad bistórica de España. Porrúa, México, 1954.

Cervantes, Miguel de: El ingenioso hidalgo Don Quijote de la Mancha. Edición de la Asociación de Academias de la Lengua Española, Madrid, 2005.

Cervantes, Miguel de: Novelas Ejemplares. Juan Bautista Avalle Arce (ed.). Castalia, Madrid, 1982.

Cervantes, Miguel de: Los trabajos de Persiles y Sigismunda. Juan Bautista AvaLLE ArCE (ed.). Castalia, Madrid, 1969.

Erasmo de Rotterdam: Elogio de la locura. Aguilar, Barcelona, 2007.

Figueredo, Álvaro: Vida y obra de Miguel de Cervantes Saavedra. Comisión de Cultura de Pan de Azúcar / Comisión pro-edición de las obras de Álvaro Figueredo, Maldonado, 1986. 
GaOs, José: Cervantes novelista, dramaturgo y poeta. Planeta, Barcelona, 1979.

HatzFeld, Helmut: El Quijote como obra de arte del lenguaje. Madrid, Consejo Superior de Investigaciones Científicas, 1966.

Hauser, Arnold: El manierismo, crisis del renacimiento. Guadarrama, Madrid, 1971.

Menéndez Pelayo, Marcelino: Interpretaciones del Quijote (Discurso leído en la Real Academia Española, en 29 de marzo de 1904, contestando al de recepción de don José María Asensio) en: Interpretaciones del Quijote. Edición nacional de las obras completas de Menéndez Pelayo VI Estudios y discursos de crítica histórica y literaria I, Santander, 1941, pp. 303-323.

Peña Martín, Cecilio: En el último mundo cervantino. En: Asomante, $\mathrm{n}^{\circ} 4$, San Juan de Puerto Rico, 1962, pp. 61-68.

Peña Martín, Cecilio: Hacia el sentido del Persiles. Edición del autor, Montevideo, 1998.

Rosales, Luis: Cervantes y la libertad. Editorial Trotta, Madrid, 1996

Salas, Alberto M. y Miguel A. Guerin (eds.): Floresta de Indias. Losada, Buenos Aires, 1970.

Singleton, Max: El misterio del Persiles. En: Realidad, n 5, Homenaje a Cervantes, Buenos Aires, septiembre-octubre de 1947, pp. 237-53.

Valbuena Prat, Ángel: Historia de la literatura española. Tomo II. Gustavo Gili, Barcelona, 1953. 